\title{
Cineastas vascos en la diáspora: el caso de Jon Villelabeitia, pionero del cine en la Patagonia argentina
}

\author{
Euskal zinemagileak diasporan:
}

Jon Villelabeitiaren kasua, Zinemaren aitzindaria argentinako Patagonian

Basque diasporic filmmakers:

The case of Jon Villelabeitia, Pioneer of cinema

in the Argentinian Patagonia

\author{
Josu Martínez ${ }^{\star}$ \\ $\mathrm{UPV} / \mathrm{EHU}$
}

RESUMEN: El objetivo de este artículo es cartografiar la figura y la obra de Jon Villelabeitia, cineasta cuyo nombre ha estado hasta ahora completamente ausente en los estudios sobre el cine vasco. Villelabeitia fue un pionero del cine en la Patagonia argentina, con una carrera que abarca una extensa obra documental desde los años 60 hasta los años 90 . El presente estudio, fruto de un largo trabajo de arqueología filmica, propone un análisis histórico de su obra, contextualizándola y comparándola con la experiencia de otras personas de origen vasco que han hecho cine en el continente americano.

PALABRAS CLAVE: cine; País Vasco; emigración; patrimonio.

ABSTRACT: The purpose of this article is to map the figure and work of Jon Villelabeitia, a filmmaker whose name has been absent in studies about Basque cinema. Villelabeitia was a pioneer of cinema in Argentine Patagonia, with a career spanning an extensive documentary work from the 60s to the 90s. The present study, wich is a result of a long work of film archeology, proposes a historical analysis of his work, contextualizing and comparing it with the experience of other Basques who have made films in the Americas.

KEYWORDS: cinema; Basque Country; emigration; heritage.

\footnotetext{
* Correspondencia a / Corresponding author: Josu Martínez. Departamento de Comunicación Audiovisual. Fac. de CC. Sociales y de la Comunicación de la UPV/EHU. Barrio Sarriena s/n (48940 Leioa) - josu.martinez@ehu.eus - https://orcid.org/0000-0001-5167-8485

Cómo citar / How to cite: Martínez, Josu (2020). «Cineastas vascos en la diáspora: el caso de Jon Villelabeitia, pionero del cine en la Patagonia argentinan, Zer, 25(48), 45-64. (https://doi.org/10.1387/zer.21035).

Recibido: 25 julio, 2019; aceptado: 3 febrero, 2020.

ISSN 1137-1102 - eISSN 1989-631X / (c) 2020 UPV/EHU

(c) (7) Esta obra está bajo una licencia
} 


$$
\begin{array}{r}
\text { Jon } \\
\text { no lleva h. } \\
\text { Mi amigo } \\
\text { no tiene partes mudas } \\
\text { de que avergonzarse. } \\
\text { Está tan hecho } \\
\text { de piedras y estrellas, } \\
\text { que cuando ya no esté, } \\
\text { dejará su sombra en el aire } \\
\text { Y habrá que bajarla a machetazos. } \\
\text { (Jorge Vilardo) }
\end{array}
$$

\section{Introducción}

Los estudios sobre el cine vasco viven una interesante etapa de profundización, revisión y reescritura. Superando las grandes obras de los pioneros de los años 80, marcadas en buena medida por los debates sobre la ontología del concepto (Unsain, 1985; Zunzunegui, 1985), la estabilización de una producción cinematográfica continuada, y el desarrollo de instituciones como la UPV/EHU (semillero de investigadores) y la Filmoteca Vasca, han hecho posible estos últimos años la aparición de un número considerable de investigaciones sobre diferentes aspectos del binomio formado por el cine y los vascos y las vascas. Muestra de la vitalidad y diversidad de los enfoques actuales cabe citar, por ejemplo, la obra de Stone y Rodriguez (2015), realizada desde un prisma político-cultural; los estudios de De Pablo sobre la relación del nacionalismo con el cine (2017); las investigaciones sobre la estructura del sistema audiovisual de Azpillaga (2013) y Manías-Muñoz (2015), así como diversos trabajos articulados desde la perspectiva de género (De Miguel, 2015; Fresneda y Agirre, 2018).

Junto con ellos, también viene despuntando otra línea de investigación poco desarrollada hasta ahora: la arqueología fílmica. En los últimos tiempos, este enfoque ha propiciado importantes hallazgos, rescatando películas y autores desconocidos u olvidados hasta la fecha que, en ocasiones, han hecho variar la misma cronología de la historia del cine vasco. Destacan entre ellos los descubrimientos realizados en París por Josu Martinez (2012 y 2015): «Gure sor lekua» (André Madré, 1956), primera cinta hablada en euskera, y «Euskadi» (René Le Henaff, 1936), documental experimental en 3D producido por Louis Lumière. También cabe señalar el hallazgo en Madrid de una copia extraviada de «Sinfonía Vasca» (Adolf Trotz, 1936), realizado por Andoni Elezcano, (2012) y de diferentes documentales producidos y encontrados en países extranjeros, tales como «Im lande der Basken» (Herbert Brieger, 1944), rescatado por Teresa Sandoval en Alemania (2000), o «Basker» y "Bonde i Baskerland» (Dan Grenholm y Lennart Olson, 1963), hallados por Argibel Euba en Suecia (2015). 
El presente artículo se inscribe dentro de esta línea de investigación, poniendo sobre la mesa el nombre y la obra de un cineasta ignoto: el vizcaíno Jon Villelabeitia, pionero del cine en la Patagonia argentina, con una extensa obra documental entre las décadas de 1960 y 1990. El objetivo principal de esta investigación es realizar una primera aproximación a su figura y situarla en el mapa de la cinematografia vasca, contextualizándola y comparándola con la experiencia de otras personas de origen vasco que han hecho cine en el continente americano.

\section{Metodología}

Este trabajo se aborda con un enfoque histórico, proponiendo un análisis descriptivo del autor y su obra. Hemos basado la recopilación de datos en la relectura de fuentes documentales, la realización de entrevistas personales, y el visionado de las obras de Jon Villelabeitia conservadas por la familia y la Universidad Nacional de la Patagonia. Todo ello se hizo durante una estancia de investigación en la Universidad Nacional de la Patagonia (UNPSJB), en mayo de 2019. Concretamente, pudimos consultar el archivo personal del cineasta y los archivos de los periódicos argentinos El Patagónico, Crónica y El Nacional; y así mismo realizamos cinco largas entrevistas personales a Marina Villelabeitia (hija), Xabier Villelabeitia (hijo y auxiliar de filmación), Hugo Arizmendi (cineasta, socio en la productora «Patagonia filmes»), Carlos Medina (Responsable de la Dirección de Medios Audiovisuales de la Universidad Nacional de la Patagonia y antiguo asistente) y Marta Díez (periodista local).

Además de todo ello, hemos trabajado también con numerosas fuentes documentales referidas a los demás cineastas diaspóricos a los que hace referencia el artículo. En cuanto a las fuentes primarias, destacan la consulta de todos los números de 1924 de las publicaciones vasco-argentinas «La Baskonia» y «Nación vasca» (año en que se proyectaron los films vascos de Blazy en Argentina y Uruguay), una entrevista personal que realizamos a Antton Ezeiza en diciembre de 2009 (Ezeiza, 16-12-2009), y en el caso de Segundo Cazalis, la consulta de la documentación referida a "Los hijos de Gernika» (archivo de la fundación Sabino Arana), el manuscrito inédito de Joseba Sarrionandia «Algunos apuntes sobre Segundo Cazalis» (2013), y la correspondencia mantenida con Begoñe Cazalis (nieta de Segundo) entre enero y marzo de 2013.

\section{Emigrantes, exiliados y aventureros: cineastas vascos en el continente americano}

La relación entre los medios audiovisuales y la diáspora o el exilio ha sido estudiada a nivel global desde diferentes perspectivas (Naficy, 1995; Sinclair \& 
Cunnigham, 2000). Por el contrario, en el País Vasco, son escasos los trabajos que abarcan este ámbito. Destacan los estudios de Amezaga (2007) sobre el consumo del canal de satélite Canal Vasco entre los vascos latinoamericanos, y el compendio de artículos reunidos por Rodríguez (2012) bajo el título «Exilio y cine», analizando la representación del exilio en películas vascas y españolas. Por otra parte, dentro de los estudios de caso, encontramos la monografia sobre el film "Gure sor lekua», realizado en 1956 y destinado a los vascos de la diáspora (Martínez, 2015).

En sus estudios sobre las cinematografias de diáspora y exilio, Naficy (2001) calificaba como «cine acentuado» aquel creado por cineastas emigrados o exiliados que, de alguna manera, utilizan el audiovisual como vehículo estético de la experiencia de estar lejos del país natal. En ese sentido, sus obras transmitirían una doble identidad, pareja a la de sus autores: "As partial, fragmented, and multiple subjects, these filmmakers are capable of producing ambiguity and doubt about the taken-for granted values of ther homes and host societies» (2001:13).

Aún no se ha investigado sistemáticamente la historia de los vascos que por razones bien sean políticas, económicas, o bien de aventura, han hecho su carrera cinematográfica fuera del país. Y hay razones para pensar que son más de los que conocemos: la imposibilidad de filmar en el País Vasco durante buena parte del siglo xx (por falta de industria y/o de libertad), la incesante emigración producida durante décadas, y algunas experiencias heterogéneas de las que se tienen datos apuntan en esa dirección. Sería pues, en esta familia de «cineastas diaspóricos» donde se situaría la figura de Jon Villelabeitia. A continuación, detallamos las desiguales trayectorias de algunos de ellos.

\subsection{Julian de Ajuria}

Uno de los principales nombres vascos de los primeros años de la historia del cine fue el ubideztarra Julián de Ajuria (1886-1965), quien, sin embargo, desempeñó toda su carrera lejos de casa, en Argentina.

Hijo del herrero de Ubidea, en las faldas del monte Gorbea, Ajuria emigró en 1906 a Buenos Aires con la obsesión de hacer fortuna (Echevarrieta, 1998). Comenzó en el naciente negocio del cine como comentarista de películas, y tras asociarse con el pianista Mario Gallo y el distribuidor Pablo Epstein, dio el salto a la producción, creando entre los tres "El fusilamiento de Dorrego» (1908) y «La revolución de mayo» (1909), considerados como los primeros filmes argumentales de la cinematografia argentina.

En 1912 creó su propia productora, la Sociedad General Cinematográfica, que también importaba películas para su distribución. Así, gracias a la idea de alquilar las 
cintas en lugar de comprarlas, como era costumbre en la época, fraguó una considerable fortuna, la cual siguió creciendo gracias al éxito de algunas de sus películas, convertidas hoy en clásicos del cine mudo argentino, como «Nobleza gaucha» (1915).

Poco a poco Ajuria se fue especializando en la distribución, e inventó para las películas más prestigiosas que compraba el sello «Programa Ajuria», el cual funcionó también en España durante los años de la República. Sin embargo, no abandonó su vocación creativa, y tras años intentando sin éxito interesar a productores norteamericanos en un guion suyo que relataba el épico nacimiento de la nación argentina, finalmente en 1928 decidió producir él mismo la cinta, que costó 300.000 dólares de la época (Echevarrieta, 1998). Ante la ausencia de industria cinematográfica en Argentina para realizar un proyecto de las dimensiones que pretendía, el film, pagado íntegramente por él, fue realizado en Hollywood con la estrella Jacqueline Logan en el papel principal de la amante del general Belgrano. "Una nueva y gloriosa nación», que así se llamó el film, tuvo un éxito notable de crítica y público, y queda como el principal legado del productor vasco a la cinematografia nacional argentina (Echevarrieta, 1998).

La relación de Ajuria con el País Vasco fue durante años fluida, pasando regularmente largas temporadas de vacaciones en Ubidea, según relataron sus familiares a Echevarrieta (1998). Sin embargo, más allá de algún film doméstico (se conserva en la Filmoteca Vasca una pequeña cinta rodada el día de su boda, en 1926), parece que no realizó ninguna producción ni en el País Vasco, ni de temática vasca. No obstante, su nombre aparece en la prensa vasco-argentina de 1924, como uno de los facilitadores de la exhibición de los filmes vascos del padre Edmond Blazy, otro asunto ignoto de la historia de la cinematografia vasca, que sin duda amerita una investigación en profundidad ( $U$ Un film de asuntos vascos será exhibido en el teatro San Martín», 1924).

\subsection{Harry Abadia Urrustoi}

Coetáneo de Ajuria, Harry Abadia Urrustoi (D’Abbadie d'Arrast, en francés) es otro de los grandes nombres vascos de los primeros años del cinematógrafo. Nacido en 1897 en una rica e importante familia (su tío-abuelo, Antoine Abadia, fue el gran mecenas de la cultura vasca del siglo XIX), pasó sus primeros años en Argentina, pero regresó siendo niño a Baigorri, donde su padre poseía el castillo Etxauzia.

Tras perder, como en casi todas las familias del país, un hermano en la I Guerra Mundial, decidió emigrar a California, también como otras muchísimas familias. Sin embargo, dada su elevada clase social, la suya fue una emigración motivada por las ganas de aventura, a diferencia de la de los miles de vascos que marcharon por motivos económicos. 
Abadia recaló directamente en Hollywood y pronto se forjó una notable carrera como actor, guionista y director. Comenzó trabajando con la actriz Gloria Swanson como asesor en «The Impossible Mrs. Bellew» (1922), y como actor en «My American Wife» (1923), pero fue a raíz de su amistad con Charles Chaplin cuando creció y se dio a conocer en el cine estadounidense. En 1922, Chaplin pasó algunas temporadas en la casa de Abadia, en Baigorri, donde escribió, con su asesoramiento sobre la realidad francesa, el singular film «A Woman of Paris» (1922), único trabajo de toda su carrera en el que no trabajó como actor, y que según Gubern sería «la primera película psicológica de la historia del cine» (2014:200). Dos años más tarde, Abadia también participaría como ayudante de dirección en la obra maestra «The Gold Rush» (1924).

Como director, realizó media docena de comedias que fueron muy bien acogidas por crítica y público, hasta el punto de ser comparado con Ernst Lubitsch (Borau, 1990). En 1927, dirigió "Service for Ladies», "A Gentleman of Paris» y "Serenade», y al año siguiente, «The Magnificent Flirt» y «Dry Martini» (esta última, película sonora). Pero fue su última cinta hollywodiense «Laughter» (1930) la que le granjeó mayor aplauso, siendo incluso nominada al Oscar en la categoría de mejor argumento.

Tras enemistarse con actores, directores y productores de Los Angeles, Abadia regresó al País Vasco e, instalado en Baigorri, trató de incursionar en el cine español. En 1934, dirigió «La traviesa molinera», cinta protagonizada por su esposa Eleanor Boardman, que cosechó excelentes críticas (Borau, 1990). Sin embargo, tampoco en Europa consiguió estabilizar una carrera duradera, y retirado entre Baigorri y los casinos de Montecarlo, murió en 1968.

\subsection{Segundo Cazalis}

Segundo Cazalis Goenaga nació en Cuba (1924), hijo del famoso pelotari de Markina Segundo Cazalis Areitio. Retornó con su madre a Bilbao siendo apenas un bebé y allí pasó sus primeros años, hasta que, tras caer Bilbao en 1937, fue evacuado. Volvió a cruzar la frontera en 1938, y se alistó voluntario en el Ejército Republicano, donde combatió unos meses hasta exiliarse de nuevo, ante la ofensiva final de los fascistas. En Francia, fue recluido en un campo de concentración.

Tras un periplo por diferentes países gracias a su nacionalidad cubana, obtenida por su nacimiento, se instaló en Venezuela, donde comenzó a trabajar en el diario El Nacional. Como corresponsal fue uno de los pocos periodistas internacionales que consiguió entrevistar a Fidel Castro y sus rebeldes en la Sierra Maestra, simpatizando inmediatamente con ellos (Sarrionandia, 2013). 
Tras el triunfo de la Revolución, establecido de nuevo en la isla, destacó como uno de los periodistas más populares del nuevo periodo. Su columna «Siquitrilla», publicada en el periódico Revolución (1960-1964) era la más leída de Cuba, y esto le granjeó una amplia simpatía, pero también una desconfianza cada vez mayor por parte de Fidel Castro (Sarrionandia, 2013). La ruptura entre ambos se produciría finalmente en marzo de 1964, cuando Castro le señaló directamente en un discurso público. En un fragmento, el comandante decía:

Encendedor de candelas, fue quien encendió aquella polémica tan inoportuna como innecesaria sobre cine y sobre arte, a destiempo, cuando nosotros estábamos ocupados de muchos problemas. Y yo quiero que me digan si debemos abandonar todos los planes económicos de la Revolución y la defensa del país ( ) para dedicarnos a discutir sobre arte y sobre cine. Realmente a nosotros no nos podrán arrastrar a eso; porque esas cuestiones pueden esperar diez años si se quiere; nadie nos puede obligar ni tiene derecho a obligarnos. ( ) Y este señor cree que es lo mismo echar a pelear a críticos de cine que echar a pelear a hombres de la Revolución. («Discurso de Fidel», 1964)

Tras entrevistarse con el Che Guevara, Cazalis entendió que era hora de volver a Venezuela, donde vivió hasta su muerte. Sin embargo, del periodo cubano queda una película escrita por él: el corto de ficción «Alfredo va a la playa» (1963), producido por la ICAIC para el mexicano Alfonso Arau.

Pasarían cuatro años hasta que Cazalis realizase su film más importante: un documental político de media hora que reivindicaría la historia de Euskadi desde la guerra civil hasta 1968, fecha del estreno. Acompañado en el guion por Paul de Garat (sobrenombre de Alberto Elosegi), Jokin Intza y Xabier Leizaola, la cinta se tituló «Los hijos de Gernika. La lucha del pueblo vasco por su libertad»), y fue construida a base de imágenes del País Vasco durante la Guerra Civil, y del Aberri Eguna celebrado en Pamplona el año anterior, donde se podía ver que la represión continuaba, con la policía atacando a los manifestantes. El filme fue patrocinado y auspiciado por EGI (PNV), y circuló como elemento de propaganda por diversos países y numerosos centros de la Diáspora Vasca.

Cazalis falleció en Caracas, poco antes de la llegada al poder de Hugo Chávez. No se le conocen más películas, pero durante sus últimos años destacó como periodista de prestigio en el diario El Universal y dejó escrito un libro inédito de título El australopitecus desobediente (Cazalis, 2013).

\subsection{Antton Ezeiza}

Antton Ezeiza (1934-2011) es conocido sobre todo por su inmensa labor teórica y práctica en pro de lo que él llamaba un «cine nacional vasco», cuya principal 
característica era que debía de ser obligatoriamente en euskera. En ese sentido fue uno de los grandes pioneros del país, tanto como coordinador de la serie «Ikuska» (1978-1984), como el largometraje de ficción «Ke arteko egunak» (1989), primera película en euskera que se estrenó en el Festival de San Sebastián, obteniendo además el Premio Donostia (Martinez, 2014). Antes de ello también tuvo una interesante carrera como cineasta en Madrid, siendo parte de la generación del «Nuevo Cine Español», y rodando cuatro largometrajes producidos por su (entonces) amigo Elías Querejeta.

Sin embargo, muchas veces se olvida su etapa del exilio. A comienzos de la década de los 70, tras años perteneciendo al PCE, Ezeiza conoció en Madrid a militantes y abogados de ETA, con los que congenió de inmediato. Evolucionó hacia posiciones abertzales de izquierda, y tras el asesinato de Carrero Blanco, tuvo que tomar el camino del exilio, si bien él siempre alegó como motivo de su partida un sentimiento de «ahogo existencial» (Ezeiza, 2009).

Tras pasar un tiempo en Cuba, donde se relacionó con lo más granado del Nuevo Cine Latinoamericano, Ezeiza recibió el encargo de hacer una película histórica «antimperialista» por parte de los gobiernos de Cuba y México (cuando el «septenio» del presidente Echeverría basculaba hacia la izquierda). Descartados diferentes personajes, Ezeiza se decantó finalmente por contar la épica vida del héroe mexicano de origen vasco Xabier Mina, quien se levantó contra los españoles en el siglo XIX.

Así nació «Mina, viento de libertad» (1976), película de gran presupuesto para la época, en la que Ezeiza quiso terminar el relato de una manera «internacionalista» (Ezeiza, 2009), creando un paralelismo entre la ejecución de Mina, y la del militante de ETA Txiki Paredes Manot, acaecida un año antes. Concretamente, la cinta acaba con el pelotón de soldados españoles fusilando al héroe mexicano mientras suena como un aire militar la melodía del Eusko gudariak (himno de los combatientes vascos que el mismo Txiki cantó una y otra vez mientras lo mataban), y antes de los títulos de crédito, se rotula en la pantalla el poema que dejó Txiki la víspera de morir: «Mañana, cuando yo muera, no me vengáis a llorar. Nunca estaré bajo tierra, soy viento de libertad».

Dos años más tarde, Ezeiza aún realizaría otra película en México: una adaptación de la novela negra «El complot mongol», la cual se estrenó solo en aquel país (Angulo, Beloki, Rebordinos \& Santamarina, 2009).

En 1978 Antton Ezeiza regresó a San Sebastián, pero no por mucho tiempo. A mediados de los años 80 le tocaría otra vez exiliarse, esta vez al País Vasco Norte. Allí realizó un par de documentales para EKIN, organización internacional de la Izquierda Abertzale que no figurarían nunca en su filmografia oficial, y que, hoy en día, están en paradero desconocido. 


\section{Jon Villelabeitia, cronista patagónico}

Nada se ha escrito en el País Vasco sobre Jon Villelabeitia (1934-1991). Tras una exhaustiva búsqueda, no hemos encontrado ni una sola línea sobre él. El nombre de Villelabeitia ha estado ausente en todos los estudios referidos al cine y los vascos. Pero, ¿quién fue realmente Villelabeitia?

\subsection{UN NIÑO DE LA GUERRA EN BUSCA DE NUEVOS MUNDOS}

Jon Villelabeitia Villelabeitia nació en 1934 en el caserío Kondebaso de Trobika, barrio de Mungia. Tercero de cinco hermanos, además de la pequeña explotación agrícola, la familia poseía un taller de bicicletas, pero a raíz de la Guerra Civil y los bombardeos que asolaron Bizkaia, tuvieron que dejar la casa, hecho que marcó los primeros años de vida de Jon.

A pesar de un paso por la escuela jesuita caracterizado por «palos, palos y más palos» (M. Villelabeitia, 2019), y de sufrir raquitismo en las dificiles condiciones económicas de la posguerra (X. Villelabeitia, 2019), según relatan sus hijos, Villelabeitia añoraba su infancia en el País Vasco como una patria perdida feliz y bucólica que recuerda a los "campesinos felices de Virgilio", que citaba Bernardo Atxaga en su novela «Soinujolearen semea» (2003). "Nos hablaba de la paz del caserío, de un río de agua cristalina en el que se bañaba, del viejo molino, los pájaros silvestres con los que jugaba» (M. Villelabeitia, 2019).

Con la esperanza de encontrar un futuro más próspero, en 1951, los dos hermanos mayores, Manuel y Josefina, decidieron embarcarse en el barco «Monte Udala» con destino a Argentina. Sin embargo, en el último momento, Josefina se echó atrás, y Jon, que apenas contaba con 17 años, tomó su lugar. Su hijo Xabier liga esta decisión a su sentimiento vasquista: "Yo estoy seguro de que emigró para no hacer el servicio militar español. Como era, le hubiera sido imposible jurar bandera, y yo creo que por eso escapó y se echó a la aventura» (X. Villelabeitia, 2019). Fuera ésta u otra su motivación principal, lo cierto es que Villelabeitia devino en desertor, por lo que, durante años, no pudo volver a su país natal. Sus hijos conocieron el País Vasco en viajes realizados exclusivamente con la madre comodorense, hasta que, finalmente, recibió la «amnistía» en 1977 y pudo regresar.

Llegados a Argentina, Manuel y Jon recalaron en Córdoba, donde vivía una hermana de su madre. Allí Jon tuvo una presencia activa en la colectividad vasca, destacando como txistulari, y aprovechó para terminar sus estudios secundarios y seguir cursos de cine en el cineclub local. En 1959, trabajando de capataz para una empresa de electrificación italiana, recaló en Comodoro Rivadavia, la prin- 
cipal ciudad de la provincia patagónica de Chubut. Tras un rápido progreso, la empresa le ofreció un puesto de gerente en Perú. No obstante, para entonces el vasco había encontrado pareja en la Patagonia, y declinó la oferta para quedarse a vivir allí.

En efecto, Villelabeitia contrajo matrimonio con Casilda Suárez Richars en 1962. Ella era «una niña bien de la sociedad comodorense» (M. Villelabeitia, 2019), hija de un gallego que había hecho fortuna y una galesa. En cambio, el vasco era un joven de carácter raramente independiente que llegaba de la nada. Al no tener ningún pariente, sus padrinos de boda fueron los guipuzcoanos Michel Garate y María Teresa Garriz, exiliados nacionalistas llegados tras la guerra. El primer hijo de la pareja, Xabier, nació el año siguiente. Después vendrían Marina (1965), Roxana (1967) y Santiago (1977).

Sus hijos lo recuerdan como un padre atípico: muy autónomo, muchas veces ausente y con una filosofia de vida poco común en una sociedad construida por gentes venidas a hacer dinero con el petróleo. «Papá se caracterizaba por su terquedad, por su fuerte sentimiento vasquista, y yo creo que también comulgaba de alguna manera con la memoria anarquista de la «Patagonia trágica» de los años 20-30» (M. Villelabeitia, 2019).

El matrimonio de Villelabeitia se rompió en 1978 y esto acentuó su condición de outsider en la provincia. También su manera de vivir. «Hasta que se separaron, de alguna manera, le sostenía el suegro. Cuando se separaron se quedó solo y se hizo aún más independiente, viviendo con muy poco dinero" (M. Villelabeitia, 2019). Para entonces llevaba ya años intentando dedicarse al cine. Una labor que le hacía aún más rara avis en aquel campamento petrolero.

\subsection{Chubut: lugar Sin Cineastas, Lugar CON historia Vasca}

Comodoro Rivadavia, donde recaló Villelabeitia, es la ciudad más poblada e importante de la Patagonia austral: motor económico de toda la región y corazón de una fértil zona hidrocarburífera. Situada en la costa atlántica de la provincia de Chubut, con un clima desértico y violentamente ventoso, el descubrimiento de petróleo en 1907 supuso un boom que alcanzaría su cenit en los años 60, época en la que se dobló la población.

Sin embargo, antes del feliz hallazgo, Chubut podía haber sido, como bien ha señalado Altonaga (2018), una colonia vasca que se llamaría «Eskal Berria» (algo así como la nueva Euskal Herria) y conservaría la lengua y modo de vida de los vascos. En 1897 el ingeniero bilbaíno Florencio Basaldua entregó un detallado proyecto al presidente Juan Argentino Roca, proponiéndole la colonización de un 
territorio de 166.000 metros cuadrados por parte de los vascos, que se financiaría a través de la creación de un banco vasco en Argentina. El propósito de Basaldua era llevar a 10.000 personas en tres años, con la idea no de hacer fortuna (aún no se había descubierto el petróleo), sino de preparar la independencia del País Vasco en América, igual que preparaban los polacos la de Polonia, o los irlandeses la de Irlanda (Altonaga, 2018). Para ello, tomaba como modelo y antecedente la colonización galesa de otra zona cercana, al norte del río Chubut. Según Altonaga, a principios del siglo $\mathrm{xx}$, el $72 \%$ de la población en la Patagonia argentina era de origen galés, y aún hoy, se estima que quedan entre 5.000 y 12.000 personas que conservan el galés como lengua materna. Sea como fuere, evidentemente, el proyecto de «Eskal Berria» no fructificó, y cuando Villelabeitia llegó a Chubut, sin ninguna noticia de esta historia, no se encontró con una nueva Euskal Herria, sino con una joven y rica ciudad petrolera en expansión, poblada por aventureros de origen diverso.

En ese contexto de fiebre petrolera, en un lugar remoto y distante de los grandes centros culturales como Buenos Aires o Santiago de Chile, la idea de hacer cine en la Patagonia se antojaba como una quimera. Así, las únicas representaciones audiovisuales provenían, o del canal de televisión Canal9, o de profesionales enviados desde Buenos Aires.

Evidentemente, en el cine comercial argentino producido en Buenos Aires, la Patagonia había aparecido en diversas películas desde la década de los treinta. Según Escobar, la mayoría de estos filmes «daban cuenta de una Patagonia épica donde los personajes moldeaban a la región — trabajo y sacrificio mediante- transformándola en una espacialidad productiva, plena de posibilidades de progreso» (Escobar, 2011). Gasel, por su parte, afirma que la Patagonia, como representación literaria, siempre se ha asociado mayoritariamente con la idea del viaje (2011). Este imaginario de «lo exótico", o mejor dicho "nuestro rincón exótico", caracterizado por el si loin si proche de la mirada capitalina, guarda cierta similitud con la representación de lo vasco que se ha realizado históricamente sobre el País Vasco por parte del cine extranjero, especialmente el francés (Martinez, 2015). En ese sentido, es interesante el testimonio dado por el propio Villelabeitia en una entrevista a un medio local tras ser preguntado por sus motivaciones al realizar cine: «Quiero poder lograr los aspectos diferentes de nuestra desconocida Patagonia, que la gente de todo el país vea la geografía, clima, actividades artísticas, culturales, así como nuestra realidad económica y social, para dejar de lado la imagen distorsionada que tienen de nosotros» («Diálogo con nuestros artistas: Jon Villelabeitia», 1974).

Se trataría, pues, de proyectar una mirada autóctona y centrípeta, en oposición a los estereotipos propios de la mirada exterior. No en vano, según diversos testimonios, el único cineasta local que en los años 60-70 batallaba para realizar una carrera cinematográfica en la región era Jon Villelabeitia. 


\subsection{Patagonia films: Cine en el CAMPamento}

A finales de 1968, Villelabeitia monta «Patagonia Films», una pequeña productora con la cual firmará sus trabajos, principalmente encargos de empresas petroleras y otros proyectos sociales de la región. Parece que no fue siempre fue fácil mantenerse profesionalmente de la realización de documentales. Quien fuera su socio durante tres años, el cineasta Hugo Arizmendi, relata así la experiencia que compartieron:

Nos comparábamos con «El vasco de la carretilla», porque éramos tercos, luchadores, afanosos... Queríamos hacer cine, pero no teníamos dinero de hacer nuestros proyectos personales. Hablábamos mucho de un guion que el vasco quería hacer de ficción. Pero acabábamos siempre en el documental local. Fue muy difícil, ganábamos poco dinero y lo hacíamos todo. Filmar, revelar, cortar la película, compaginarla, meter el sonido... como el hombre orquesta. (Arizmendi, 2019)

En una entrevista en el diario El Patagónico en 1974, Villelabeitia afirmaba: «Hacer cine no es como hacer chorizos en una fábrica, aunque a veces el parecido sea notable. Yo vivo de ello, o mejor dicho, sobrevivo", ante lo que el entrevistador comentaba que muchos le consideraban «un resentido». En otro reportaje sobre los artistas de Comodoro, publicado en Crónica en 1976, el cronista decía sobre Villelabeitia: «Debe luchar contra la incomprensión y el desdén de ciertos grupos sociales que no aprecian su talento, por más disciplinado y ascético que sea» («Sobre los artistas: los fariseos del arte», 1976).

Lo cierto es que Villelabeitia tenía una concepción artística de su trabajo, y que le daba a la estética y la construcción dramática del documental un valor mucho mayor del que, probablemente, esperaban quienes le encargaban el trabajo. Así, en la citada entrevista de El patagónico el periodista señala que «su interés estético a veces va en detrimento de la objetividad del documentalista». La respuesta de Villelabeitia no puede ser más elocuente:

Estoy íntimamente convencido de que agregar un poco de belleza no deteriora esa realidad objetiva. En la naturaleza de las cosas siempre hay belleza, a veces oculta, subyacente. (...) Yo no escribo poesía, pero trato de hacerlo con la cámara y especialmente con todos los actos de mi vida. (...) No me vengas con floripondios. La poesía para que hoy te entiendan, debe sacudir, conmover, morder o abofetear. («Dialogo con nuestros artistas: Jon Villelabeitia», 1974)

Como señala Arizmendi, la manera de trabajar de Villelabeitia era «amateurmente profesional». Paliaba con grandes dosis de trabajo y método una inmensa 
escasez de medios. Su hijo Xabier, quien, tras la partida de Arizmendi a París, le acompañaría como asistente siendo apenas un niño, recuerda: «Podía pasar 24 horas seguidas en la moviola, sin dormir. No se cuidaba. Era extremadamente obsesivo con el trabajo» (X. Villelabeitia, 2019).

Villelabeitia realizó una media de uno o dos documentales de 45-60 minutos al año desde 1971 hasta 1991. La mayor parte de ellos fueron encargos de las grandes empresas petroleras, en los que siempre intentaba buscar un interés visual: «Entraba a sitios de alto riesgo a grabar, sitios con gran número de accidentes laborales, como un kamikaze, solo por buscar la mejor toma» (X. Villelabeitia, 2019). No obstante, también filmó diversos personajes y acontecimientos sociales locales de importancia, lo que convierte su obra en la memoria filmica colectiva de la gran época petrolera de la Patagonia sur.

\subsection{Los filmes Petroleros: el hito del Cóndor}

Como señala Arizmendi, dadas las precarias condiciones en las que trabajaban, generalmente no hacían copias de los trabajos realizados, de manera que en muchos casos la única copia de los filmes de Villelabeitia está (si es que se conserva aún) en la empresa que los encargó. Es el caso de "Panorama petrolero», un film para la empresa pública YPF en 1976 que se emitió en el Canal 9 de la televisión, y sobre el que el diario El Patagónico publicó un comentario de inusitado entusiasmo bajo el título «Poesía dinámica en un film documental sobre petróleo de J.V. Beitia» («Panorama petrolero", 1976).

Tras comparar el trabajo nada menos que con «El hombre de Aran» de Robert Flaherty, el periódico señalaba: «Documental riguroso, conducido con un estilo personal claro y definido, sin concesiones demagógicas ni falseamientos, el film de Villela Beitia insiste en ciertas tomas en algunos ángulos inverosímiles, con una cuota de sentido estético que sorprende a cada instante por su reiteración y su belleza» («Panorama petrolero», 1976).

No obstante, el trabajo más reconocido de Villelabeitia fue sin duda «El pozo Cóndor 10», realizado en 1972 motu proprio y vendido a YPF. Este documental narra un peligroso incendio de un pozo petrolero (el «Cóndor 10»), y la odisea que supuso apagarlo, mostrando el proceso completo desde el primer intento, efectuado con un operativo en base de concentración de agua, el segundo por medio de polvo químico, y el último (también con agua).

"Fue un infierno en el que papá pudo volar por los aires», recuerda su hijo Xabier (2019), pues en su intento de registrar el acontecimiento, Villelabeitia se expuso al fuego de manera temeraria. Según Arizmendi: «Se acercó 
tanto al fuego que se le derritió el lente de su cámara. Se habló mucho de esta película esos años. Una obra maestra de narración y del valor y agallas de un cineasta en medio del fuego tratando de captar todo lo que acontecía.» (Arizmendi, 2019)

Exhibida en la dirección general de YPF, la empresa estatal decidió sonorizarlo en Buenos Aires y tirar copias de $35 \mathrm{~mm}$ para las salas de cine y de $16 \mathrm{~mm}$ para pasar en escuelas e instituciones. Así, la película se enseñó en todo el país y también internacionalmente como cinta educativa para ingenieros y técnicos.

\subsection{El gandul: la vuelta al Cabo de Hornos}

Además de los filmes petroleros, Vilellabeitia filmó documentales sobre ciudades de la región (Caleta Olivia, Comodoro...), acontecimientos (primer vuelo directo a Buenos Aires), o personalidades locales («el cura Corti»: salesiano italiano que alcanzó gran fama en la Patagonia por su labor creando escuelas en barrios desfavorecidos). Sin embargo, entre todos ellos destaca, por su carácter más personal, el proyecto del velero «Gandul», sobre el que realizaría dos películas.

El Gandul era un pequeño y raquítico velero de apenas 8 metros de eslora, en el que media docena de aventureros (entre ellos Villelabeitia) decidieron embarcarse en 1984 para realizar la proeza de cruzar el Cabo de Hornos: «algo así como la versión marina de subir el Everest» (X. Villelabeitia, 2019). Sería la primera expedición de un barco tan pequeño en intentar la hazaña, y para ello, la tripulación, capitaneada por el joven Gustavo Díaz, ensayó un viaje previo de prueba, en el que navegaron desde Comodoro hasta la península de Valdés, en una travesía de 10 días. De ella nacería la película "Un edén a Barlovento», que se estrenó en marzo de 1985 en prime time en el Canal 9.

Justamente en esas fechas, los seis tripulantes del Gandul embarcaban de nuevo, esta vez sí, para intentar realizar la vuelta al Cabo de Hornos. El acontecimiento tuvo amplia repercusión en la prensa local, y varios medios interrogaron a Villelabeitia sobre la película que pensaba realizar narrando la travesía. Separándose de nuevo de la visión "exótica» proyectada desde el exterior sobre la Patagonia, contestaba así:

El objetivo del film es contribuir al conocimiento de nuestra realidad. Va a ser realizado con un profundo sentido regional, tratando de volcar la realidad patagónica que nos circunda, y que, a veces, es tratada con mucha frivolidad por los medios de la Capital. Generalmente esos medios toman siempre la trastienda de nuestra región, una Patagonia mágica cuando no truculenta, que, aunque sea parte de la realidad, no aporta mucho a nuestras necesidades 
específicas. («Mañana parte el velero comodorense Gandul II en una inédita aventura», 1985)

Finalmente, tras un viaje que se le alargó hasta los tres meses, el Gandul consiguió su propósito y culminó la travesía, dando vuelta al Cabo de Hornos. Sin embargo, la dureza de la aventura se reveló muchísimo mayor de lo prevista, y una serie de percances, unidas a condiciones climatológicas adversas, y a la falta de consistencia de la embarcación, estuvieron a punto de costar la vida a la tripulación en más de una ocasión. Xabier Villelabeitia lo relata con una mezcla de admiración y angustia: «Fue una hazaña histórica. Pero también fue algo realmente suicida. Se les acabó el agua, pasaron 15 días comiendo solo polenta... Pasamos días sin noticias de ellos, porque también se les rompió la radio, y claro, te temías lo peor» (X. Villelabeitia, 2019). Tras regresar, Jon Villelabeitia narró el viaje de la siguiente manera:

Salimos de Comodoro hace tres meses hacia Puerto Deseado y Rio Gallegos. Por el estrecho de Magallanes llegamos a Punta Arenas y de allí bajamos a Ushuaia y Puerto Williams, para seguir por los canales seguimos dentro de un marco de belleza natural imponente. Lograda la autorización chilena, emprendimos el paso entre las islas Lenox y Navarino, y al día siguiente encaramos el Cabo de Hornos. Seguimos por el Atlántico hasta las bahías Aguirre y Buen Suceso. La isla de los Estados, nuestro próximo anclaje fue una experiencia muy interesante, ya que estuvimos en ella tres días. Para aumentar las raciones, salimos a explorarla varias veces. Una vez cazamos una cabra salvaje e hicimos un asado. La etapa más dura fue la de retorno al continente, por el estrecho de Le Maire, que tiene corrientes encontradas y violentas, de nueve nudos. Allí nos tomó un temporal de fondo durante cinco días con sus noches, en que estuvimos listos para zozobrar, pero sin rendirnos. Fue algo que no puede explicarse con palabras. Nos quedamos sin alimentos a bordo, sin gas ni radio y tuvimos que racionar el agua. En definitiva, llegamos a Rio Gallegos bastante apaleados. Estos días de borrasca y algunas caídas de gente al mar, incluido el capitán, se contabilizan entre los peores momentos pasados. («El desafio náutico y la proyección del viaje», 1985)

En la misma entrevista, Villelabeitia explicaba que, dada la cantidad de horas que había filmado, realizaría un documental de 150 minutos que dividiría en tres capítulos. Ya para entonces había llegado a un acuerdo con la ATC (televisión pública nacional) para que emitiera la miniserie documental. No obstante, el film nunca se emitió. Ni siquiera lo vio nadie. Villelabeitia terminó el montaje y la cinta desapareció. Al parecer, el cineasta tuvo un duro desencuentro con el capitán del barco, con quien la relación se había degradado durante la travesía, y más de una vez había dicho que acabaría por destruir él mismo su film. Visto que nunca más se supo de él, sus colaboradores y allegados opinan que efectivamente Villelabeitia destruyó la obra 
de su vida, por no entregársela al capitán, en un gesto que recuerda al mito de Gartxot y Mikelot:

No sé qué sucedería entre ellos, pero debió de ser algo que le dolió tanto que tomó una decisión drástica. Él era así de cabezón. Y a mí me lo dijo; «voy a quemar la película y se la voy a devolver al mar», así que estoy seguro de que lo hizo. (X. Villelabeitia, 2019)

\subsection{Director de medios audiovisuales de la Universidad Pública}

En 1985 Villelabeitia recibió una propuesta de parte del Rector de la Universidad Nacional de la Patagonia San Juan del Bosco (UNPSJB). Querían armar un centro de medios audiovisuales que se ocupara transversalmente de todo lo referido al dominio de la imagen y el sonido dentro de la universidad, y acudieron a él para que dirigiera el proyecto. Su hijo recuerda las contradicciones que la oferta le provocó a Villelabeitia:

Dudó mucho. Era reacio de meterse en un trabajo formal, donde tendría un jefe y unos horarios que cumplir. Creía que perdería su independencia y sobre todo su creatividad. Yo le decía que estaba loco. Que tenía ya más de 50 años, y que iba siendo hora de que tuviera un sueldo fijo, y no tener que preocuparse siempre de si llegaría a fin de mes. Al final accedió. (Xabier, 2019)

Villelabeitia formó un equipo de media docena de trabajadores, que se ocuparían de realizar audiovisuales educativos y de la asistencia técnica en las aulas. Carlos Medina - actual director del centro- ingresó entonces como asistente. "Comenzamos rodando en $16 \mathrm{~mm}$, como hacía él. Pero no teníamos medios realmente. Imagínate, incluso el vasco había inventado un sistema sin fin para revelar las películas en su propia bañera... Así que nos pasamos al video: VHS y Umatic» (Medina, 2019).

Hasta 1991 Villelabeitia y su equipo realizaron media docena de documentales de investigación con fines educativos:

Seguíamos a tiempo real el ritmo del trabajo de campo de investigación y el vasco trabajaba con un método y un guion de hierro, así que la producción era lenta. Para realizar un documental fácilmente pasábamos 9 meses o un año. (Medina, 2019)

Los principales títulos de esta época son «Tras las huellas del pasado» en 1986 (sobre el descubrimiento de la los rastros de un dinosaurio en la ciudad de Sarmiento), «Palas al viento» en 1987 (sobre la construcción, entonces pionera, de mo- 
linos de energía eólica), «Comodoro mira al mar» en 1989 (sobre los niños de las escuelas de Comodoro), "Campanita de mi aldea» en 1990 (sobre la inseminación ovina en una pequeña aldea, vista desde los ojos de los niños), y, finalmente, «La fragua de los sueños» en 1991. Esta cinta mostraba una colonia pastoril donde los inmigrantes se instalaron y crearon una nueva cultura basada en el laboreo de la tierra y la explotación del ganado. Para ello, los artistas Guillermo Caroli Williams y Pompey Romanov y los indígenas tehuelches dialogaban y actualizaban las relaciones y los símbolos de sustrato aborigen de la cultura patagónica (Medina, 2019).

Villelabeitia fue encontrado muerto en su estudio por su hijo Xabier el 13 de julio de 1991, aparentemente de un paro cardíaco. Tras su fallecimiento, «La fragua de los sueños» fue estrenada en el Festival de cine de Lausana FIFART, donde había sido seleccionado en categoría internacional. Le quedaron por realizar sus proyectos más personales. A ellos se refería así en la entrevista antes citada: "Quiero ir a recorrer toda América, cámara en mano, para acumular experiencias y conocer de cerca a todos los pueblos americanos» («Dialogo con nuestros artistas», 1974).

\section{Conclusiones}

El objetivo principal de este artículo es dar a conocer el nombre y la obra de Jon Villelabeitia, recuperando así una figura ausente para la historiografia sobre el cine y los vascos. En ese sentido, la primera constatación es su condición de pionero del cine en la Patagonia argentina. Además, es destacable que fue uno de los principales cronistas de su identidad durante más de 20 años, recogiendo con su obra un mosaico audiovisual que reúne los principales hitos de la cultura local (el petróleo, la obra de los salesianos, el primer vuelo a Buenos Aires, el patrimonio indígena, la aventura del Gandul, la universidad...) convirtiendo su obra en una pieza insustituible de la memoria colectiva sobre la época dorada de la Patagonia sur.

Al mismo tiempo, hemos intentado situar a Villelabeitia dentro de una genealogía de cineastas vascos que desarrollaron su carrera fuera del país. Así, hemos realizado una retrospectiva sobre la trayectoria de los principales realizadores vascos diaspóricos, aportando además, en el caso de Cazalis y Ezeiza, datos no conocidos hasta ahora. En la mayoría de los casos de los autores analizados, es patente el vínculo emocional que mantienen con el país natal, aunque esto se manifiesta en diferentes maneras y grados. Abadia, por ejemplo, vuelve constantemente a Baigorri, pero esto no se refleja de manera alguna en su trabajo. Ajuria tampoco realiza ningún film de temática vasca, sin embargo, es facilitador y organizador de proyecciones dedicadas a la colectividad. Cazalis, por el contrario, entra de lleno en ese terreno y construye una película abiertamente política que pasa a ser el testimonio audiovisual de una parte del exilio abertzale. Por último, Ezeiza, más sutilmente, utiliza un tema propio del país de acogida, para hablar finalmente (de una manera «internacionalista», dirá 
él) de su propio país de origen, siendo el suyo el caso que más se acerca al concepto de «cine acentuado» que acuñó Nacify.

En cuanto a Villelabeitia, a priori, parece obvio que en sus películas no hay rastro de ese "cine acentuado", ya que consagró toda su extensa obra a temáticas de la realidad local de la Patagonia. No obstante, el hecho de que el apego al País Vasco (recordemos que durante años no puede volver por ser desertor del ejército) aparezca unánimemente en los testimonios recogidos como una de sus principales características, unido a su insistencia en las entrevistas concedidas sobre su motivación de retratar la Patagonia más allá del cliché exótico y «distorsionado» del visitante, con una mirada interior que reflejara la complejidad del lugar, nos hacen pensar en la hipótesis de que, a la hora de filmar la Patagonia, Villelabeitia tuviera presente, como muchos vasquistas, la imagen superficial, sesgada o falsa que se ha dado en ocasiones sobre el País Vasco desde fuera (Martinez, 2019). En ese sentido, su socio Arizmendi recordaba que «Su obsesión era Gernika. Las mentiras que se decían sobre que los vascos habían quemado Gernika» (Arizmendi, 2019). Por otro lado, resulta paradójico que sea precisamente un inmigrante vasco quien intente con su cine corregir la visión de los realizadores argentinos de Buenos Aires, quienes en principio deberían de tener una mirada más cercana. Así, el cine de Villelabeitia sí que conectaría con la definición de cineasta diaspórico de Naficy, cuando señala que, por ser estos sujetos fragmentados y múltiples, son capaces de producir dudas sobre los valores dados por sentados en los países de acogida.

Por último, cabe destacar como conclusión "práctica» de este trabajo de investigación, el acuerdo alcanzado con la familia y la UNPSJB, para que las películas que conservan ambos sean trasladadas al País Vasco y sean conservadas y digitalizadas en la Filmoteca Vasca, otorgándole así a Villelabeitia no solo un lugar en la literatura académica sobre cine vasco, sino un lugar donde su obra pueda descansar y ser estudiada por futuros investigadores.

\section{Referencias bibliográficas}

Agirre, K. \& Fresneda, I. (2018). Wychodząc z «baserri». Queerowe kino baskijskie dzisiaj. Kwartalnik Filmowy, 101-102, 223-230.

Altonaga, K. (2018). Patagoniara Hazparnen barrena. Iruñea: Pamiela.

Amezaga, J. (2004). Satelite bidezko nortasunak. Latinoamerikan Canal Vasco ikusten. Donostia: Utriasque Vasconiae.

Angulo, J., Beloki, M., Rebordinos, J.L., Santamarina, A. (2009). Antxon Eceiza: cine, existencialismo y dialéctica. Donostia: Filmoteca Vasca.

Arizmendi, H. Entrevista personal. 23 de mayo, 2019.

Atxaga, B. (2013). Soinujolearen semea. Iruñea: Pamiela. 
Azpillaga, P. (2013). Euskadiko ikus-entzunezko industriaren erronkak. En Jakin, 194-195, 61-76.

Borau, J.L. (1990). El caballero D'Arrast. Donostia: Filmoteca Vasca.

Cazalis, B. (2013, enero-marzo). Correspondencia personal.

De Miguel, C. (2015). Itxoiten dut o el tratamiento de lo femenino en el cine vasco. En Joxean Fernandez (coord.), Cine vasco: tres generaciones de cineastas (pp. 143-154). Donostia: Filmoteca Vasca.

De Pablo, S. (2017). Creadores de sombras: ETA y el nacionalismo vasco a través del cine. Madrid: Tecnos.

Dialogo con nuestros artistas: con Jon Villelabeitia. (11 de abril, 1974). Diario El Patagónico.

Díez, M. Entrevista personal. 24 de mayo, 2019.

Discurso de Fidel (4 de marzo, 1964). Revista Bohemia.

El desafio náutico y la proyección del viaje (16 de junio, 1985). Diario El Patagónico.

Escobar, P. (2011). Cine e historia: la Patagonia en imágenes (1936-1976), Trelew: Jornada.

Echevarrieta, A. (1998). Julian de Ajuria. Una vida de cine. Bilbao: Diputación Foral de Bizkaia.

Ezeiza, A. Entrevista personal. 16 de diciembre, 2009.

Gasel, A. (2012) De cuerpos y territorios. Itinerarios de la Patagonia Austral en la narrativa argentina reciente (1982-2008) Ensenada: Universidad Nacional de La Plata.

Gubern, R. (2014). Historia del cine. Madrid: Anagrama.

Manias-Muñoz, M. (2015). Euskarazko zinemaren produkzioa eta finantzazioa (2005-2012): hamaika fikziozko film luzeren azterketa ekonomikoa. Leioa: UPV/EHU.

Mañana parte el velero comodorense Gandul II en una inédita aventura. 15 de febrero, 1985. Diario Crónica.

Martinez, J. (2014). Ikuska saila: ostarte bat laino itsasoan. En Jakin, 200, 95-112.

Martinez, J. (2015). Gure (zinemaren) sor lekua. Euskarazko lehen filmaren aurkikuntza, historia eta analisia. Leioa: UPV/EHUren argitalpen zerbitzua.

Martinez, J. (2016). Searching for Ramuntcho: foreign filmmakers in French Basque Country. En Communication E Society, 29(3), 19-31.

Medina, C. Entrevista personal. 21 de mayo, 2019.

Naficy, H. (2001). An accented cinema. Exilic and diasporing filmmaking. Oxford: Princeton University Press.

Panorama petrolero. 18 de diciembre, 1976. Diario El Patagónico.

Sarrionandia, J. (2013). Algunos apuntes sobre Segundo Cazalis. Manuscrito inédito.

Sinclair, J. \& Cunnigham, S. (2000). «Go with the flow: diasporas and media». Television $\mathcal{E}$ New Media 1 (1): 11-31.

Sobre los artistas: los fariseos del arte (11 de diciembre, 1976). Diario Crónica.

https://doi.org/10.1387/zer.21035 
Stone, B \& Rodriguez, P. (2015). Cine vasco, una historia política y cultural. Salamanca: Comunicación Social.

Rodriguez, M.P. (2013). Exilio y cine. Bilbao: Universidad de Deusto.

Un film de asuntos vascos será exhibido en el teatro San Martin. 31 de julio de 1924. Nación Vasca.

Unsain, JM (1985). El cine y los vascos. Donostia: Eusko Ikaskuntza.

Villelabeitia, M. Entrevista personal. 20 de mayo, 2019.

Villelabeitia, X. Entrevista personal. 22 de mayo, 2019.

Zunzunegui, S. (1985). El cine en el País Vasco. Bilbao: Diputación Foral de Bizkaia. 